\title{
Research on Green Supply Chain Management and Enterprise Performance in Taiwan's Electronics Industry
}

\author{
Su-Wen Wang', Shih - Kuan Chiu ${ }^{2}$ \\ ${ }^{1}$ Feng Chia University \\ ${ }^{2}$ Feng Chia University College of Business \\ E-mail address: domaluck@,gmail.com ,E-mail address: skchiu@mail.fcu.edu.tw
}

\begin{abstract}
The increase in greenhouse gases $(G H G)$ in the atmosphere has led to global warming. Climate change is an international environmental issue. Therefore, companies should pay more attention to carbon management strategies in their supply chains. It also requires major suppliers to disclose their greenhouse gas emissions and climate change strategies through CDP. These suppliers include some large electronics manufacturers in Taiwan. The focus of this research is to understand the carbon management strategy in the green supply chain of Taiwan's electronics industry. Based on the collected strategies, a questionnaire was compiled and mailed to listed electronics companies in Taiwan to understand how Taiwanese electronics companies deal with carbon management in their supply chains. In this study, the collected data were analyzed and processed through descriptive statistical analysis, one-way analysis of variance, Pearson product difference correlation, and multiple stepwise regression analysis. And draw the following conclusion: Director of Electronics Industry- The views on overall green supply chain management and overall company performance are in the middle and high levels, there are significant differences in "marriage", "gender", "age", "education" and "work experience", there is a positive correlation between all aspects, and there are significant differences, there is a significant correlation between the two. And has the predictive ability. The results of this study also indicate that the most important strategies for large electronics companies to manage their supply chain carbon risks are "green product design," "material replacement," "energy efficiency," and "reducing packaging and reusability." And these companies have already begun to implement these carbon management strategies. Finally, based on the research process and conclusions, specific suggestions are made to provide references for Taiwan's electronics-related industries and future researchers.
\end{abstract}

Keywords: Green supply chain; Carbon management strategy; Electronics industry

\section{INTRODUCTION}

This is an open access article under the CC-BY-NC license.

The global climate is constantly changing, and the imbalance between economic development and ecological design has caused serious pollution and environmental damage. Therefore, with the increasing public awareness of ecological design and the efforts of various countries to formulate environmental laws and regulations, if companies want to maintain a competitive advantage in the global trend, they must pay attention to environmental issues (Kannan, Khodaverdi, Olfat, Jafarian 
and Diabat, 2013 ), which also means that the company must introduce the concept of green supply chain management in its original production activities to reduce environmental damage and achieve a balance between environmental and economic performance. (Hsu and $\mathrm{Hu}, 2008$; Diabat and Govindan, 2011).

In particular, Green Supply Chain Management (GSCM) is part of sustainable development (Baumgartner and Zielowski, 2007). It can prompt the company to review the organization to adjust all aspects of overall operations (Parker, Fraunholz, Zutshi, Crofts, 2011; Guo and Zheng, 2012). Therefore, many companies are facing the need to implement green supply chain management in response to the shift in global consumer awareness (Zhu and Sarkis, 2013).

However, Taiwan has gradually turned to green procurement. In the process of manufacturing products, product materials will be passed along the supply chain (Li, Zeng, Guan, Jian, and Huang, 2009). Through a series of green processes, such as green design, green manufacturing, and green packaging, products with low environmental pollution are produced, and the environmental performance of the product life cycle is improved (Wu and Barnes, 2015). Companies that implement environmental innovations can reduce damage to the natural environment (Hu and Hsu, 2013; Shi, Koh, Baldwin, and Cucchiella, 2012; Kannan et al., 2013).

In addition, when discussing whether green supply chain management will bring performance to the company. From the past literature on supply chain management, it is found that there is still a vague relationship between supply chain management practices and corporate performance. For example, Zhu, Sarkis, and Lai (2013) pointed out that the use of supply chain management practices by Chinese automakers will only improve environmental and operational performance but will not significantly improve organizational performance. Green, Zelbst, Meacham, and Bhadauria (2012) studied the impact of color supply chain management of American manufacturers on performance. The study found that the use of color supply chain management practices will improve environmental performance and business performance, and then improve corporate performance. Therefore, with the increasing awareness of ecological design among people in various countries and the formulation of environmental laws and regulations in various countries, if companies want to maintain a competitive advantage under the global trend, they must pay attention to environmental issues (Kannan et al., 2013). ). This also means that companies must introduce the concept of green supply chain management in their original production activities to reduce environmental damage and strike a balance between environmental and economic performance (Diabat and Govindan, 2011; Hsu and $\mathrm{Hu}, 2013$; $\mathrm{Wu}$ and Barnes), 2015).

In short, different from traditional supply chain management, green supply chain management emphasizes the integration of environmental thinking into supply chain management, including product design, raw material procurement, and selection, manufacturing process, finished product transportation, and product scrap management. . (Srivastava, 2007). In terms of performance, the traditional supply chain only focuses on improving the company's own business performance; green supply chain management must be integrated into the entire supply chain and the overall environment for consideration, and to improve environmental performance, economic performance, operational performance, and non-entity Performance is the goal (Eltayeb, Zalani, and Ramayah, 2011; El-Fekey, 2015). Therefore, in order to understand the relationship between green supply chain management in Taiwan's electronics industry and corporate performance, this study takes Taiwan's electronics industry executives as the research object to explore the relationship between green supply chain management practices and corporate performance and its current status. Put forward, feasible suggestions in academics and practice.. 


\section{LITERATURE REVIEW}

\subsection{Research hypothesis}

The purpose of this research is to understand the discussion of green supply chain management and corporate performance. The researchers put forward the research hypothesis as follows:

Hypothesis 1: Electronics industry executives with different demographic variables have significant differences in perceptions of green supply chain management.

Hypothesis 2: Electronic industry executives with different demographic variables have significant differences in corporate performance perception.

Hypothesis 3: Green supply chain management is significantly related to corporate performance.

Hypothesis 4: Green supply chain management has an impact on corporate performance.

\subsection{Survey objects and sampling methods}

\subsubsection{Questionnaire pre-test}

In this study, a total of 30 pre-test questionnaires were sent out, 25 questionnaires were returned, two invalid questionnaires were deducted, 23 valid questionnaires and the total recovery rate was $76.6 \%$.

\subsubsection{Questionnaire survey}

this study used e-mail to send the questionnaire online. In this study, a total of 300 formal questionnaires were sent, of which 195 were returned, and 18 invalid questionnaires were deducted. There are 176 valid questionnaires. The total effective response rate was $58.7 \%$.

\subsection{Research tools}

This research tool mainly has three parts, the "Green Supply Chain Management Scale," "Corporate Performance Scale," and "Basic Personal Information." The contents of the questionnaire are explained as follows:

\subsubsection{Green Supply Chain Management Scale}

The research refers to Eltayeb et al. (2011). After Shi, Koh, Baldwin, and Cucchiella (2012); Hu \& Hsu (2013); Kannan et al. (2013); Wu and Barnes (2015), and other documents, the scale of green supply chain management is divided into four categories and 17 projects. Cronbach's coefficient of the scale is 0.815 to 0.85 , which is between 0.78 and .90 , which is a medium to a highly reliable research tool.

\subsubsection{Enterprise Performance Scale}

The research refers to Eltayeb et al. (2011). After Shi, Koh, Baldwin, and Cucchiella (2012); Hu \& Hsu (2013); Kannan et al. (2013); Wu and Barnes (2015), and other documents, the enterprise performance scale is divided into three dimensions and 17 questions. Score points on the Likert scale. The Cronbach alpha coefficient of the total scale is 0.823 , which is between .78 and .90 . It is a medium to a high-reliability research tool.

\subsubsection{Basic personal information}

The basic personal data in this study includes five items: "gender," "marital status," "age," "education level," and "working experience." 


\subsubsection{Measurement method}

The method of questionnaire measurement in this study is based on the Likert 5-point scale, ranging from "very consistent," "conforming," "normal," "non-conforming," and "very nonconforming" respectively from 5 to 1 point. The higher the score of the subjects, the higher the influence of the subscale and the overall dimension; on the contrary, the lower the score, the lower the influence of the subscale and the overall dimension.

\subsection{Data analysis methods}

Data analysis uses SPSS 22.0 software package for statistical analysis to understand the correlation of the research variables, $\mathrm{p}<0.05$ indicates the significance level of the hypothesis test, including descriptive statistics, to understand the characteristics of the sample; one-way analysis of variance, to understand the electronic industry executives Personnel have a significant difference between green supply chain management and company performance; Pearson correlation analysis to understand the correlation between green supply chain management and corporate performance; multiple regression analysis to understand the impact of green supply chain management on company performance.

\section{QUESTIONNARE TEST ANALYSIS RESULTS}

\subsection{Personal background information}

The majority of the interviewees in this study are women, with a sample size of 90 , with a percentage of $51 \%$; marital status is the largest, with a sample number of 136 , with a percentage of $76.9 \%$; most of the age is $41-50$ years old, with a sample number of 87 , The percentage is $49.3 \%$; the majority of educational backgrounds are masters, the sample number is 91 , the percentage is $51.4 \%$; the working experience is the most with $10-15$ years, the sample number is 74 , the percentage is $41.5 \%$.

\subsection{Current status analysis of green supply chain management and corporate performance}

\subsubsection{Analysis of the current status of green supply chain management}

Table 1 shows four aspects: the overall average is 3.86. The research results show that the electronic industry executives' views on the overall management of the green supply chain are between "agree" and "normal" levels. Each average quantity is different, but they are consistent with every dimension of green supply chain management.

Table 1. Summary table of current status analysis of green supply chain management

\begin{tabular}{lclc}
\hline Green Supply Chain Management & Facet Mean & Standard Deviation & Sort \\
\hline Environmental management & 3.86 & 0.89 & 2 \\
Green procurement & 3.93 & 0.91 & 1 \\
Customer cooperation & 3.80 & 0.96 & 4 \\
Ecological design & 3.84 & 0.93 & 3 \\
Total table & 3.86 & 1.29 & \\
\hline
\end{tabular}

\subsubsection{Analysis of the current status of corporate performance}

Table 2 shows that there are three aspects: the overall average is 3.89. The research results show that the opinion of the electronics industry executives on the company's overall performance score is 
between "agree" and "average" in the upper middle. Although the average values are different, they all reach a consensus on all aspects of company performance.

Table 2. Summary table of analysis of current corporate performance

\begin{tabular}{llll}
\hline Enterprise performance dimension & \multicolumn{2}{l}{ Mean standard deviation } & Sort. \\
\hline Environmental performance & 3.87 & 0.86 & 2 \\
Economic performance & 3.86 & 0.87 & 3 \\
Operating performance & 3.93 & 0.90 & 1 \\
Total table & 3.89 & 1.13 & \\
\hline
\end{tabular}

\subsection{Difference analysis of demographic variables to green supply chain management}

Hypothesis 1: Electronic industry executives with different demographic variables have significant differences in perceptions of green supply chain management

1. In terms of environmental management: different "marital status" have significant differences $(p<0.01$ ), and the evaluation of married people is higher than that of unmarried people.

2. In terms of green procurement: different "working years" have significant differences $(p$ $<0.001)$.

3. In terms of customer cooperation: different "education levels" have significant differences ( $p$ $<0.001$ ). A master's degree is higher than a doctoral degree, a doctoral degree is higher than a university, and a university is higher than a junior college.

4. In terms of ecological design: different "ages" have significant differences $(\mathrm{p}<0.01)$, and the assessment of 36-40 years old is higher than 46-50 years old.

Hypothesis 2: Electronic industry executives with different demographic variables have significant differences in their views on company performance

1. In terms of environmental performance: different "genders" have significant differences ( $p$ $<0.001)$

2. In terms of economic performance: different "ages" have significant differences $(p<0.01)$.

3. In terms of operational performance: different "education levels" have significant differences $(\mathrm{p}<0.001)$.

4. In terms of ecological design: different "ages" have significant differences $(p<0.01)$, and the assessment of 36-40 years old is higher than $46-50$ years old. related

Hypothesis 3: Green supply chain management and corporate performance are significantly

Table 3 shows the correlation analysis between the green overall supply chain management and company performance, the correlation analysis between the green overall supply chain and the various levels of company performance, and the correlation between all levels of the company. The correlation analysis and research results of the green supply chain show that:

1. Each level of green supply chain management has a significant positive correlation with all aspects of company performance 0.1 and has reached a significant level of difference, and all aspects are close Related. In other words, the higher the green supply chain management, the higher the company's performance.

2. Therefore, if green supply chain management can be improved, it will also indirectly improve corporate performance.

Table 3. Correlation analysis table of green supply chain management on corporate performance 


\begin{tabular}{|c|c|c|c|c|}
\hline \multirow[t]{2}{*}{ Variable } & \multicolumn{2}{|c|}{ Environmental-Economic } & \multirow{2}{*}{$\begin{array}{l}\text { Operational } \\
\text { Performance }\end{array}$} & \multirow{2}{*}{$\begin{array}{l}\text { Overall Corporate } \\
\text { Performance }\end{array}$} \\
\hline & Performance & Performance & & \\
\hline \multicolumn{5}{|l|}{ Environmental } \\
\hline Management & $.224 * * *$ & $.228 * * *$ & $.285 * * *$ & $.345 * * *$ \\
\hline Green procurement & $.231 * * *$ & $.4383 * * *$ & $.247 * * *$ & $.381 * * *$ \\
\hline Customer cooperation & $.170 * * *$ & $.180 * * *$ & $.180 * * *$ & $.224 * * *$ \\
\hline Ecological design & $.149 * * *$ & $.220 * * *$ & $.308 * * *$ & $.306 * * *$ \\
\hline $\begin{array}{l}\text { Overall green supply } \\
\text { chain management }\end{array}$ & $.277 * * *$ & $.340 * * *$ & $.318 * * *$ & $.426 * * *$ \\
\hline
\end{tabular}

$* \mathrm{p}<0.05, * * \mathrm{p}<0.01, * * * \mathrm{p}<0.001$

Hypothesis 4: Green supply chain management has predictive power on corporate performance

Table 4 shows the results of the collinearity test and input variables, as well as explanatory and standardized regression $\beta$ coefficients of input variables. The analysis results show that all aspects of green supply chain management can effectively predict the performance of the entire company and obtain support. There are four green supply chain management factors that will affect the overall performance of electronics industry executives. Among them, "customer cooperation" has the greatest impact, and "green procurement" has the least impact.

Table 4. Summary table of forecast analysis of green supply chain management on overall corporate performance

\begin{tabular}{lcccccccc}
\hline Variable & \multicolumn{2}{c}{$\begin{array}{c}\text { Multi-phase } \\
\text { Relationship } \\
\text { R }\end{array}$} & $\begin{array}{c}\text { Decision } \\
\text { systemo } \\
\mathrm{R} 2\end{array}$ & $\begin{array}{c}\text { Increase the amount } \\
\text { interpretation } \\
\Delta \mathrm{R} 2\end{array}$ & $\begin{array}{l}\mathrm{F} \\
\text { value }\end{array}$ & $\begin{array}{l}\text { Standardized } \\
\text { regression } \\
\text { system } \beta\end{array}$ & $\begin{array}{l}\text { Variability } \\
\text { fluctuation } \\
\text { factor VIF }\end{array}$ & $\begin{array}{l}\text { Condition } \\
\text { Index }\end{array}$ \\
\hline $\begin{array}{l}\text { Customer } \\
\text { cooperation }\end{array}$ & .716 & .513 & .408 & $959.463 * * *$ & .263 & 2.132 & 10.876 \\
$\begin{array}{l}\text { Ecological } \\
\text { design }\end{array}$ & .788 & .621 & .118 & $738.552^{* * *}$ & .226 & 1.831 & 15.064 \\
$\begin{array}{l}\text { Environmental } \\
\text { Management }\end{array}$ & .826 & .682 & .054 & $589.900^{* * *}$ & .225 & 1.616 & 16.089 \\
$\begin{array}{l}\text { Green } \\
\text { procurement }\end{array}$ & .815 & .664 & .036 & $425.320^{* * *}$ & .183 & 1.826 & 17.166 \\
\hline
\end{tabular}

\section{CONCLUSIONS AND SUGGESTIONS}

\subsection{Conclusion}

First conclusion is that this study found that electronic industry executives with different variables have a mid-to-high level of view on overall green supply chain management, and they are recognized. However, the "green supply chain management" recognized by the electronics industry executives has significant differences in marital status, age, education level, and working years. And supervisors who are married and 36-40 years old with a master's degree and have worked for more than 16 years give the highest evaluation.

Second, this study found that electronics industry executives with different variables have a mid-to-high level of view on overall corporate performance. The "corporate performance" recognized by the electronics industry executives has significant differences in gender, age, 
education, and years of work. Men and supervisors who are 41-50 years old and have a doctorate degree, and have worked for more than 16 years give the highest evaluation.

Third, this study found that green supply chain management and company performance are both moderately positively correlated, and both reach significant levels. It shows that there is a close relationship between green supply chain management and company performance, and the relationship between "green procurement" and "economic performance" is the closest. It means that the higher the green supply chain management level of the electronics industry executives, the more positive their corporate performance. Therefore, if electronic companies improve green supply chain management, they can also improve corporate performance. And start with the strategy of "green procurement" and "economic performance."

Forth, this study found that the collinearity problem is not serious, and the input variables and interpretation results are the most relevant and the most important predictive variables for customer cooperation; the regression analysis results show that all levels of green supply chain management and the overall performance of the company have positive predictive power. Said that the higher the level of various aspects of green supply chain management in the electronics industry, the higher the overall corporate performance. Among them, the "customer cooperation" aspect has the strongest influence. Therefore, green supply chain management has predictive power on corporate performance. It can start with the strategy of "customer cooperation."

In addition, this research also shows that most electronics companies in Taiwan have already begun to implement carbon management strategies such as "green product design," "material replacement," "energy efficiency," and "reduce packaging and reusability".4.2 Suggestions.

\subsection{Suggestions}

\subsubsection{Recommendations on research objects}

The research takes into account the constraints of manpower and time, and it may be difficult to fully demonstrate the true thoughts of the research objects. In the future, you can expand the research object and scope as well as different regions and analyze and compare whether there is a difference between green supply chain management leaders and company performance.

\subsubsection{Recommendations on research methods}

This study uses the method of investigation and research to conduct quantitative research. In the future, you can use more qualitative research methods, such as case studies, interviews, and observations, to increase the depth of research.

\subsubsection{Recommendations on research variables}

This research mainly discusses green supply chain management and corporate performance research in Taiwan's electronics industry. The topics discussed are only the status and impact of green supply chain management and corporate performance. You can expand different categories to conduct empirical research, examine differences and correlations, and analyze the impact of variables.

\section{REFERENCES}

Baumgartner, R. J., and Zielowski, C. (2007), “Analyzing zero emission strategies regarding impact on organizational culture and contribution to sustainable development, "Journal of Cleaner Production, 15(13), pp. 1321-1327.

Diabat, A., and Govindan, K. (2011), "An analysis of the drivers affecting the implementation of green supply chain management, "Resources, Conservation and Recycling, 55(6), pp. 659667.

Diabat, A., Khodaverdi, R., and Olfat, L. (2013), "An exploration of green supply chain practices and performances in an automotive industry, "The International Journal of Advanced Manufacturing Technology, 68(1-4), pp. 949-961. 
El-Fekey, S. F. (2015), "The effect of human resource development practices on creating learning organizations: An empirical study on the banking sector in Egypt, "Journal of Business and Management Sciences, 3(4), pp. 130-137.

Eltayeb, T. K., Zailani, S., and Ramayah, T. (2011), "Green supply chain initiatives among certified companies in Malaysia and environmental sustainability: Investigating the outcomes, "Resources, Conservation and Recycling, 55(5), pp. 495-506.

Green Jr, K. W., Zelbst, P. J., Meacham, J., \& Bhadauria, V. S. (2012). Green supply chain management practices: impact on performance. Supply Chain Management: An International Journal, 17(3), 290-305.

Guo, J. J., and Tsai, S. B. (2015), "Discussing and evaluating green supply chain suppliers: A case study of the printed circuit board industryin China, "South African Journal of Industrial Engineering, 26(2), pp. 56-67.

Hsu, C. W., and Hu, A. H. (2008), "Green supply chain management in the electronic industry, "International Journal of Environmental Science and Technology, 5(2), pp. 205-216.

Hsu,C.C.,Liou,J.J., andChuang,Y.C.(2013),"IntegratingDANPandmodifiedgreyrelationtheoryforthe selectionofanoutsourcingprovider,"ExpertSystemswithApplications,40(6),pp.2297-2304.

Kannan, D., Khodaverdi, R., Olfat, L.,Jafarian, A., and Diabat, A. (2013), "Integrated fuzzy multi criteria decision making method and multi-objective programming approach for supplier selection and order allocation in agreen supply chain, "Journal of Cleaner Production, 47, pp. 355-367.

Lee, W. S., Tzeng, G. H., Guan, J. L., Chien, K. T., and Huang, J. M. (2009), "Combined MCDM techniques for exploring stock selection based on Gordon model, "Expert Systems with Applications, 36(3), pp. 6421-6430.

Parker, C., Fraunholz, B., Zutshi, A., and Crofts, M. (2011), "How do Australian small and medium enterprises communicate their environmental improvement activities online?" Australasian Journal of Information Systems, 17(1), pp. 5-21.

Srivastava, S. K. (2007), "Greensupply-chainmanagement: A state-of-the-art literature review, "International Journal of Management Reviews, 9(1), pp. 53-80.

Wu, C., and Barnes, D. (2015), "An integrated model for green partner selection and supply chain construction, "Journal of Cleaner Production, 112(3), pp. 2114-2132.

Zhu, Q., Sarkis, J., and Lai, K. H. (2007), "Initiatives and outcomes of green supply chain management implementation by Chinese manufacturers, "Journal of Environmental Management, 85(1), pp. 179-189.

Zhu, Q., Sarkis, J., and Lai, K. H. (2013), "Institutional-based antecedents and performance outcomes of internal and external green supply chain management practices, "Journal of Purchasing and Supply Management, 19(2), pp. 106-117.

Wu, C., and Barnes, D. (2015), "An integrated model for green partner selection and supply chain construction, "Journal of Cleaner Production, 112(3), pp. 2114-2132.B 